\title{
Light Induced Esterification of Oleic Acid Catalyzed by Pseudomonas Cepacia Lipase
}

\author{
G. Ponnarasy, Md. Maksudur Rahman Khan, Md. Abul Kalam, and Mohd Sabri Mahmud
}

\begin{abstract}
This paper reports on new approach of light illuminated esterification of oleic acid catalyzed by an enzymatic catalyst. Immobilized Pseudomonas cepacia lipase was used as a biocatalyst. Enzyme catalyzed esterification reaction was chosen due to the wide attention from chemical and biotechnology industry. The reaction was conducted under light illumination and dark condition at same experimental condition. The result was obtained in the form of changes in oleic acid concentration throughout $2 \mathrm{~h}$ of reaction. The results indicate significant changes in rate of reaction for light illuminated reaction compare to reaction under dark condition. The initial rate of reaction for light induced and dark reaction are $1.2 \mathrm{~mol} / \mathrm{L} . \mathrm{min}, 1.1 \mathrm{~mol} / \mathrm{L} . \mathrm{min}$ respectively. Influence of enzyme amount was experimented where it shows proportional increase with the amount of enzyme. Increasing the amount of enzyme also increases the availability of active sites of enzyme therefore the probability of light illumination activating the electron transfer in oxyanion hole increases with increase in energy level of electron lone pair. The results obtained indicate that light illuminating method for enzyme activation provide good alternative for future biotechnology industry.
\end{abstract}

Index Terms-Esterification, light induced, oleic acid, Pseudomonas cepacia.

\section{INTRODUCTION}

Lipases are triacylglycerol acylhydrolases, E.C. 3.1.1.3 possess specific characteristics to catalyze ester hydrolysis reaction, esterification and transesterification reactions [1], [2]. These reactions widely explored by industries in recent years [3]. These are due to unique character of lipase structure being regiospecific, stereospecific and substrate specific [2], [4] and [5]. Furthermore, enzyme catalyzed reaction provides benefits over chemically synthesized reaction such as less energy condition by lowering the number of processes and it is environmental friendly [6].

However, due to the high enzyme production cost and low reaction rate the wide industrial application has not been implemented [7]-[9]. Therefore, researchers have been exploring the means to increase the rate of reaction by optimizing various parameters such as molar ratio, temperature, water content, immobilization method, $\mathrm{pH}$ and solvents for lipase from different sources.

Manuscript received October 7, 2013; revised December 10, 2013. This work was supported in part by University Malaysia Pahang under Grant GRS 120347

G. Ponnarasy, Md. Maksudur Rahman Khan, and Mohd Sabri Mahmud are with the Department of Chemical and Natural Resources Engineering, Universiti Malaysia Pahang, Kuantan, Malaysia (e-mail: arasy04_p@yahoo.com,_ mrkhancep@yahoo.com, mohdsabri@ump.edu.my).

Md. Abul Kalam is with Sul Ross State University EPS Department Box C139 Alpine, Texas 79832, USA (e-mail: kalam1970@gmail.com).
However, none of the researchers implement light induced enzyme catalyzed esterification reaction until date. Hence, this study aims to activate the enzyme through light irradiation. Although, so far no studies on enzyme catalyzed esterification under visible light the novel approach was supported by previous researchers work on enzyme activation under the influence of light for different model. For instance, in 1986, Ljerka Purec et al. published that the hydrogenase activity of Proteus vulgaris could be enhanced by the irradiation of light with a wavelength of $253.7 \mathrm{~nm}$. The studies also proposed that the light stimulation is irreversible reaction and the catalytic activity increases due to the conformational changes in enzyme [10], [11]. Later in 2003, Maciej Fiedorowicz et al. modified this light induced enzyme activity to study the effect of polarized and non-polarized visible light on hydrolysis of $\alpha$-amylase. The authors showed that the conformational changes of $\alpha$-amylase happened when the protein was illuminated with visible polarized and non-polarized light [12], [13].

Pseudomonas cepacia lipase was used in this study since its character as most adaptable biocatalyst. Furthermore, its crystal structure also reported by Kim et al. While $P$. glumae, R. miehei, G. candidum $C$. viscosum lipases show closed conformation where its active site structure is buried beneath a helical segment called as 'lid' and only opens up when interact with substrate [14]. Whereas, P.cepacia lipase illustrates highly open conformation made easier access of light to pass the active site of the enzyme.

Therefore, the objective of the study is to investigate the fundamental effect of light on enzymatic activity of lipases in esterification reactions. We have studied the lipase catalyzed esterification of oleic acid in the presence of commercially immobilized lipase from Pseudomonas cepacia in hexane under light and dark condition to identify the changes in rate of reaction for light illuminated enzyme catalyzed esterification reaction.

\section{Materials AND Methods}

\section{A. Materials}

$P$. cepacia lipase immobilized on chemically inert, hydrophobic sol-gel support was purchased from Sigma Aldrich (Switzerland). Ethanol, Oleic acid with an approximate purity of $99 \%$ and HPLC grade hexane were supplied by Fisher Scientific from Loughborough, United Kingdom. Sodium hydroxide was purchased from Merck KGaA, Germany. All chemicals, if not specified otherwise, were of analytical grade. 


\section{B. Equipment and Esterification Reaction}

Immobilized P.cepacia lipase was assayed in the direct esterification of oleic acid with ethanol to produce ethyl oleate and water as the end products.

Equation (1) describes the foremost esterification reaction between Oleic acid and ethanol with presence of lipase catalyst.

$$
\text { Oleic acid }+ \text { Ethanol } \stackrel{\text { Lipase }}{\longleftrightarrow} \text { Ethyl oleate }+ \text { Water }
$$

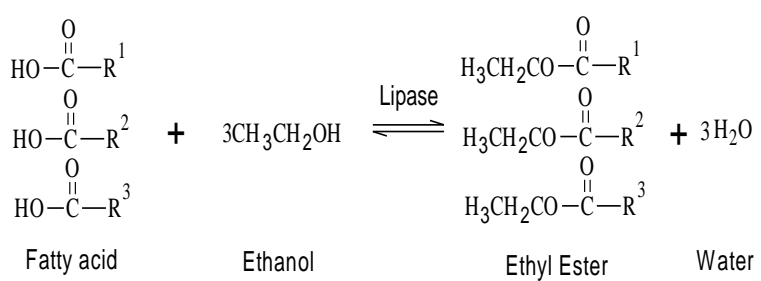

Fig. 1. Lipase catalyzed esterification reaction.

The synthesis was carried out with $120 \mathrm{mM}$ oleic acid, $120 \mathrm{mM}$ ethanol and $0.11 \mathrm{~g}$ Pseudomonas Cepacia lipase in isothermal batch type reactor with continuous stirring at 300rpm equipped with a heat transfer jacket and cooling system as shown in Fig. 2. All the reaction was conducted at $37^{\circ} \mathrm{C}$. In a typical experiment, the reactants were introduced in the reactor and heated up to the working temperature. Once the reaction temperature was reached, the reaction was activated by adding the immobilized Pseudomonas cepacia lipase into the reactor.

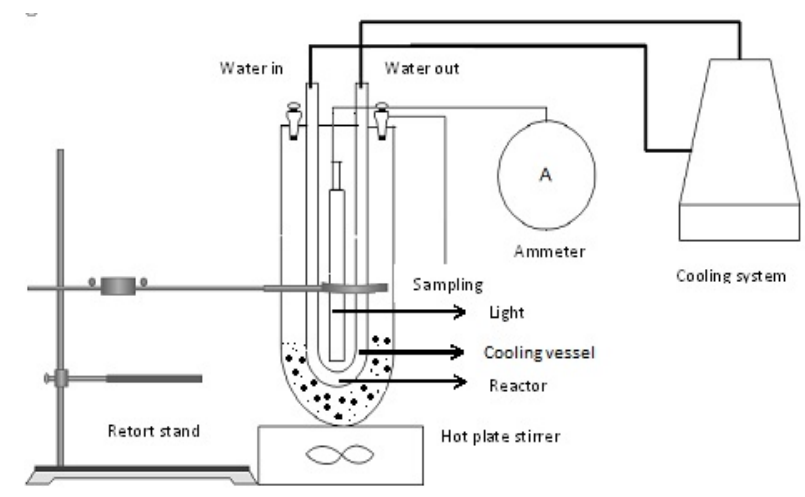

Fig. 2. Reactor setup.

\section{Analysis of Reaction Product}

The progress of the esterification was monitored by determination of the remaining oleic acid content by titrating with a $0.01 \mathrm{M}$ basic solution of sodium hydroxide. Phenolphthalein was used as the end-point indicator and a mixture of ethanol-acetone $50 / 50 \%(\mathrm{v} / \mathrm{v})$ was used as quenching agent. When the enzymatic activity stopped, the catalyst was separated by filtration, washed with ethanol $(96 \%)$ and dried. All the experiments were repeated twice.

\section{RESULTS AND DISCUSSION}

\section{A. Synthesis of Ethyl Oleate}

Fig. 3 shows the reduction in concentration of oleic acid with respect to time. The reaction was conducted under both visible light and dark condition with total reaction volume of $12 \mathrm{ml}$ hexane consist of $120 \mathrm{mM}$ oleic acid, $120 \mathrm{mM}$ ethanol with presence of $0.11 \mathrm{~g}$ immobilized Pseudomonas cepacia enzyme. As shown in Fig. 1. After 2 h of reaction more than $50 \%$ conversion was obtained for light and dark reactions. However, there is significant change in concentration of oleic acid presence in reaction volume for the first $20 \mathrm{~min}$ in light illuminated experiment. This may be due to acceleration of hydrogen transferring to histidine residue in oxyanion hole with light illumination. The crystal structure of P.cepacia lipase reported by Kim et al. illustrates open conformation structure (open lid) which made easy reachable of light on active site.

The rate was calculated using the three point differentiation formula as shown below:

$$
\left(\frac{d C A}{d t}\right)_{t_{o}}=\frac{-3 C A_{0}+4 C A_{1}-C A_{2}}{2 \Delta T}
$$

The rate was calculated by considering the initial concentration, $C A_{0}$ of oleic acid followed by two more consecutive concentrations at equally spaced time difference.

The esterification of oleic acid and ethanol with respect to (a) conversion and (b) initial rate of reaction was illustrated in Fig. 4. As expected the obtained result shows a linear increase in initial rate of reaction with an increase of enzyme amount in hexane volume. Fig. 4(a) indicates both light and dark reactions are kinetically controlled enzymatic reaction where the system behaves as homogeneous.

The initial reaction rate for $0.11 \mathrm{~g}$ of enzyme under light was $0.022 \mathrm{~mol} / \mathrm{L}$.min whereas for reaction under dark was $0.009 \mathrm{~mol} / \mathrm{L}$.min. For enzyme amount of $0.09,0.06$ and 0.03 the rate for light induced reaction were $0.018 \mathrm{~mol} / \mathrm{L} . \mathrm{min}$, $0.015 \mathrm{~mol} / \mathrm{L}$.min and $0.009 \mathrm{~mol} / \mathrm{L}$.min respectively while for dark is $0.008 \mathrm{~mol} / \mathrm{L}$.min, $0.005 \mathrm{~mol} / \mathrm{L}$.min and 0.003 $\mathrm{mol} / \mathrm{L}$.min respectively. Therefore, all the reactions under light indicate higher rate compare to dark condition. The slope value from Fig. 4(b) shows initial rate of reaction for light and dark reactions have linear increase with lipase amount, it confirms there is no mass transfer limitation present.

The value of Table I was extracted from Fig. 2. Using (1) where light has high initial rate compare to dark reaction with $1.200 \mathrm{~mol} / \mathrm{L}$. min and $1.113 \mathrm{~mol} / \mathrm{L}$. min.

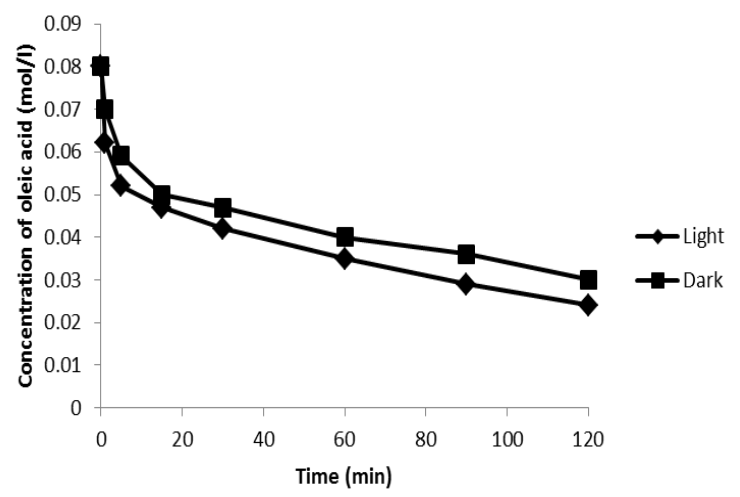

Fig. 3. Comparison for conversion of oleic acid with respect to time under light and dark condition. 


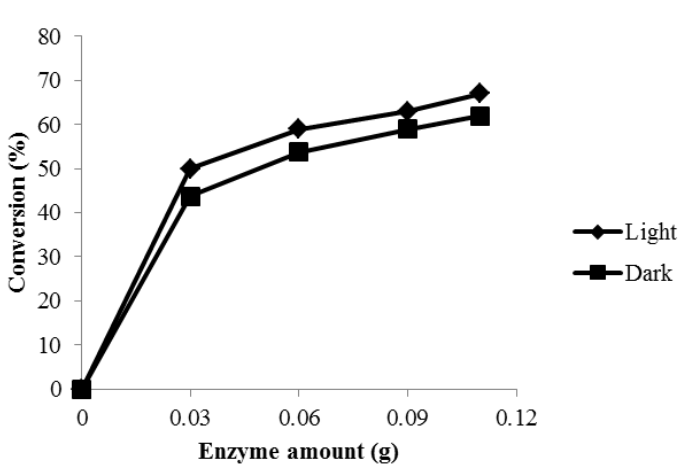

(a)

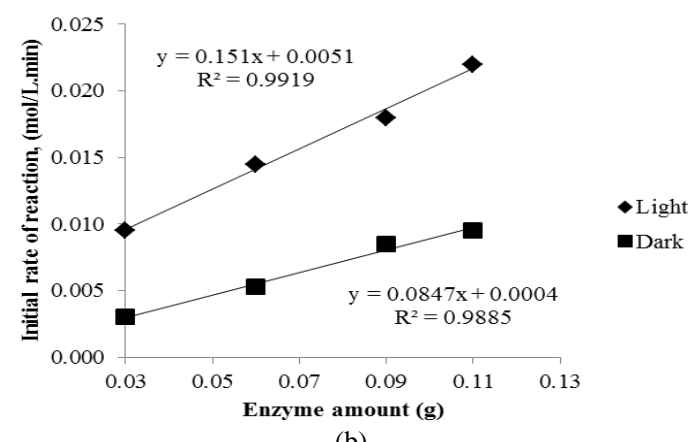

(b)

Fig. 4. Effect of enzyme amount (a) conversion, (b) Initial reaction rate on esterification of oleic acid.

TABLE I: INITIAL REACTION RATE FOR LIGHT AND DARK CONDITION

\begin{tabular}{cc}
\hline \hline Condition & $\begin{array}{c}\text { Initial rate of reaction } \\
(\mathrm{mol} / \mathrm{L} . \mathrm{min})\end{array}$ \\
\hline Light & 1.200 \\
Dark & 1.113 \\
\hline \hline
\end{tabular}

\section{B. Influence of Enzyme Amount}

The significant increase for light induced reaction could be due to excitation of electron lone pair on histidine-nitrogen during tetrahedral intermediate of oxyanion hole which could move to higher energy level resulting into facilitated passing through transition state of the process for formation of a covalent bond between histidine-nitrogen and hydrogen from serine. Therefore, the excitation of electron enhances the activity of lipase enzyme to accelerate the reaction rate [14].

\section{CONCLUSION}

The objective of this study is to evaluate on rate of esterification reaction under light illumination. It was demonstrated that light induced reaction has higher rate of reaction compared to the dark reaction. Hereafter, this method could be implemented for enzyme catalyzed hydrolysis and transesterification reaction. Unambiguously, light illumination for lipase catalyzed reactions should take into serious consideration for future of lipase enzyme catalysis especially for biofuel production.

\section{REFERENCES}

[1] L. Yun, Z. Xuan, T. Hui, Y. Yunjun, and B. H. Hameed, "Effect of pretreatment by different organic solvents on esterification activity and conformation of immobilized Pseudomonas cepacia lipase," Journal of Procecss Biochemistry, vol. 45, pp. 1176-1180, 2010.

[2] J. Geraldine and T. Satoru, Perspectives on Lipase Enzyme Teachnology, Inc, New York, Nova Science Publishe, 2009, pp. 4-6.
[3] I. L. Gatfield, R. L. S. Patterson, B. V. Charlwood, G. Macleod, and A. A. Williams, Bioinformation of Flavors, Royal Society of Chemistry, Cambridge, 1992, pp. 171-185.

[4] C. Gutierrez, A. A. Carelli, and M. L. Ferreira, "Relation between lipase structures and their catalytic ability to hydrolyse triglycerides and phospholipids," Enzyme and Microbial Technology, vol. 41, pp. 35-43, 2007.

[5] K. Bana, S, Hamab, K. Nishizuka, M. Kaieda , T. Matsumoto, and A. Kondo, "Repeated use of whole-cell biocatalysts immobilized within biomass support particles for biodiesel fuel production," Journal of Molecular Catalysis B: Enzymatic, vol. 17, pp. 157-165, 2002.

[6] N. Hilal, V. Kochkodan, R. Nigmatullin, V. Goncharuk, and L. Al-Khatib, "Lipase immobilized biocatalytic membranes for enzymatic esterification: comparison of various approaches to membrane preparation," Journal of Membrane Science, vol. 268, pp. 198-207, 2006.

[7] P. D. Maria, J. M. Sanchez-Montero, J. V. Sinisterra, and A. R Alcantara, "Understanding Candida rugosa lipases: an overview," Biotechnology Advances, vol. 24, pp. 180-196, 2005.

[8] R. K. Saxena, A. Sheoran, B. Giri, and W. S. Davidson, "Purification strategies for microbial lipases," Journal of Microbiological Methods, vol. 52, pp. 1-18, 2003.

[9] L. Purec and A. Krasna, "The activation of the Hydrogenase of Proteus Vulgaris by visible light," Biochemistry, vol. 57, pp. 1416-1421, 1967.

[10] M. Fenyo, "Theoretical and experimental basis of biostimulation," Optics and Laser Technology, vol. 16, pp. 209-215, 1984.

[11] M. Fiedorowicz and G. Chaczatrian, "Effect of illumination with the visible polarized and non-polarized light on R-Amylolysis of starches of different botanical origin," Journal of Agricultural and Food Chemistry, vol. 51, pp. 7815-7819, 2003.

[12] I. Kertesz, M, Fenyo, E. Mester, and G. Bathori, "Hypothetical physical model for laser biostimulation," Optics and Laser Technology, vol. 14, pp. 31-32, 1982.

[13] S. H. Kyu, S. D. Hae, H. K. Yeon et al., "The crystal structure of a triacylglycerol lipase from Pseudomonas cepacia reveals a highly open conformation in the absence of a bound inhibitor," Structure, vol. 5, pp. 173-185, 1997

[14] B. Jeremy, T. John, and S. Lubert, Biochemistry, 7th Ed. W. H. Freeman, 2010, pp. 257.

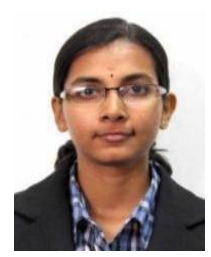

G. Ponnarasy completed her degree in chemical engineering (biotechnology) in University Malaysia Pahang, Malaysia in 2011. Currently, she is pursuing her master degree in chemical engineering (bioprocess).

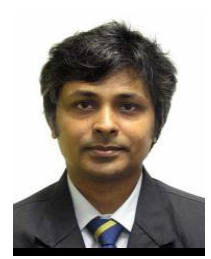

Maksudur R. Khan completed his Ph.D. in chemical engineering from National University Lvivska Polytechnika in 1997.

Since 1998 he has been working as a faculty member in Bangladesh and Malaysia. He has published more than 80 papers in reputed journals in the field of catalysis, photocatalysis, fuel cell, biodiesel and nanomaterial. Currently, he has been working as an associate professor at Universiti Malaysia Pahang, Malaysia.

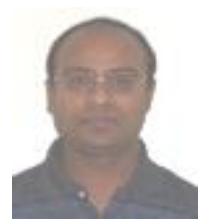

Md. Abul Kalam completed his Ph.D. in 2005 and currently working as an associate professor of Chemistry in Chemistry Department of BGPS, Sul Ross State University, Alpine, TX 97832, United States of America.

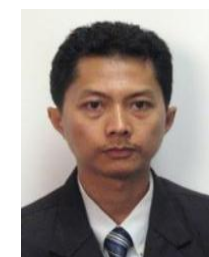

Mohd Sabri Mahmud completed his Ph.D. in chemical engineering from University of New South Wales, Sydney, Australia. Currently, he is working as a senior lecturer at Universiti Malaysia Pahang. He has worked on Kinetic studies of esterification reaction catalyzed by lipase enzyme for his Ph.D. studies. 